\title{
Escolha, estratégia e competição por escolas públicas
}

\author{
Marcio da Costa ${ }^{*}$, Mariane C. Koslinski*
}

Resumo: Usualmente, políticas que buscam estimular a liberdade de escolha de escolas por parte dos pais visam declaradamente promover melhoria educacional por meio de mecanismos competitivos e/ou de accountability. Há discussão acumulada na sociologia sobre os quase-mercados formados em políticas de escolha escolar. $\mathrm{O}$ artigo investiga os processos de escolha e de acesso escolar em um contexto que denominamos "quase-mercado oculto". No caso brasileiro, a ausência de regulação permite que severos mecanismos de segmentação se manifestem em meio à complexa hierarquia escolar existente nas redes compostas por escolas públicas "comuns". O artigo apresenta a elaboração conceitual presente na literatura internacional e nossas reflexôes para o caso brasileiro, além de resultados de uma pesquisa, especialmente de sua fase qualitativa, referente às entrevistas realizadas com professores(as), diretores(as) e com pais de alunos do Ensino Fundamental da rede municipal na cidade do Rio de Janeiro.

Palavras-chave: escolha escolar; segmentação escolar; quase-mercados; desigualdades de oportunidades escolares; desigualdades sociais.

\section{Choice, strategy and competition for public schools}

Abstract: Frequently, policies that seek to encourage parents' school choice aim to promote educational improvement by means of competitive and/or accountability mechanisms. There is a growing discussion within sociology around the quasi-markets formed with school choice policies. The paper investigates the processes of school choice and access in a context called "hidden quasi-market". In the Brazilian context, the absence of regulation allows the emergence of severe mechanisms of segmentation that take place within a complex school hierarchy existing among "ordinary" school systems. The article presents a conceptual elaboration present in the international literature and our considerations regarding the Brazilian context. It also brings some results, especially those concerning the qualitative phase of the research, including interviews with teachers, principals and students' parents from municipal elementary schools in the city of Rio de Janeiro.

Key words: school choice; school stratification; quasi-markets; inequality of educational opportunities; social inequalities.

Professor Associado da Universidade Federal do Rio de Janeiro (UFRJ), RJ, Brasil.marcioc@ pobox.com

** Professora Adjunta da Universidade Federal do Rio de Janeiro, RJ, Brasil. marianeck@yahoo. com.br 


\section{Introdução}

É grande a polêmica internacional acerca dos efeitos e das características de programas de escolha escolar (school-choice). Usualmente, políticas que buscam estimular a liberdade de escolha de escolas por parte dos pais visam declaradamente promover processos de melhoria da oferta educacional por meio de mecanismos competitivos e/ou de accountability. Mesmo na ausência de políticas de incentivo à escolha, o conceito de quase-mercado ajuda a compreender a competição de alunos por escolas e de escolas por alunos.

Nosso conceito de quase-mercado, seguindo a definiçáo de Le Grand (1991), associa a noção de competição entre agentes à observaçáo de que, nesse caso, tal competição não é ordenada, predominantemente, segundo os recursos econômicos dos contendores. Valores monetários não são a moeda corrente. Outros recursos, ou capitais, como prefeririam algumas correntes teóricas, entram mais fortemente na distribuição das oportunidades em tais mercados. Há, porém, bens simbólicos fortemente valorizados sendo distribuídos e disputa intensa por eles.

Os quase-mercados educacionais podem ser compreendidos como resultantes de uma oferta escolar claramente diferenciada, sob a qual se ajustam as escolhas de estabelecimentos escolares. Políticas de quase-mercados funcionariam a partir de mecanismos de incentivo à escolha, configurada pela oferta de um cardápio de escolas aos alunos e aos pais de alunos e pelo estabelecimento de sistemas organizados de informaçóes acerca de escolas e de tais escolhas. Pelo lado da oferta, podem ser esperadas reaçóes das escolas, buscando ajuste a um quadro competitivo, raro no âmbito das instituições públicas. Para os defensores de políticas de instituição de quase-mercados, as escolas buscariam captar estudantes a partir da oferta de uma mercadoria (educação, credenciais) diferenciada ou de melhor qualidade. $\mathrm{O}$ resultado seria, segundo essa lógica, incremento na qualidade da oferta ${ }^{1}$.

Nossos estudos têm sugerido que também no Brasil é possível falar de quase-mercados, mesmo quando não nos referimos aos disputados mercados formados por prestigiadas escolas particulares nos grandes centros urbanos ou na ausência de competição clara entre escolas públicas. Entre os amplos segmentos da população desprovida de meios de acesso a essas escolas mais demandadas, podemos encontrar renhidas lutas pela oportunidade de aceder a uma oferta

I As críticas a esses arranjos de políticas públicas, ancorados em mecanismos competitivos, costumam enfatizar certa ingenuidade quanto aos supostos efeitos virtuosos da competição na oferta de um bem público como a educação. Não há, contudo, apenas uma visão ultraliberal disponível no campo. Medidas de controle estatal frequentemente estão associadas aos quasemercados escolares formalmente constituídos. Assim, regulamentações e procedimentos de supervisão/controle são usualmente observados, buscando contrabalançar, em alguma medida, efeitos perversos que a pura e simples competição por vagas pode encetar, dado que as condições de escolha e acesso não são igualmente distribuídas entre a população. 
escolar considerada de qualidade superior às demais, no espectro daquelas às quais é plausível aspirar.

O fenômeno se expressa por dispositivos competitivos postos em ação tanto por famílias em busca de melhores chances educacionais quanto pela burocracia educacional, que têm papel ativo no processo. Nossa pesquisa dedica-se a investigar os processos de escolha e de acesso escolar em um contexto que denominamos "quase-mercado oculto". Pretendemos observar o caso brasileiro - em contraste com locais onde há políticas deliberadas de escolha escolar - e os mecanismos de segmentação que se manifestam em meio à complexa hierarquia escolar existente nas redes "comuns". Suspeitamos que, em nosso caso, a quase ausência de regras para a disputa por vagas nas escolas que atendem à imensa maioria da população promove a desigualdade de oportunidades escolares de forma mais severa que a observada em contextos criticados pelos opositores de políticas de school-choice. Enfim, o processo parece acentuar características promotoras de desigualdade social, ampliando as chances de quem já desfruta de alguma vantagem competitiva, frequentemente associada ao patrimônio de relaçóes sociais. Usamos, assim, o conceito de quase-mercado como recurso analítico para compreender o fenômeno da disputa por escolas públicas que não podem ser caracterizadas como "de elite" ou "de excelência" no contexto brasileiro.

Acreditamos que o uso do conceito de quase-mercado escolar, no caso brasileiro, sob o enfoque sociológico, exige o acréscimo do adjetivo "oculto", na ausência de políticas deliberadas que o regulamentem. Nosso quase-mercado, se conta com competição no lado da demanda, não se rebate necessariamente de forma competitiva no lado da oferta. De fato, nossas evidências não indicam a ocorrência de competiçấo por alunos entre escolas públicas. Parece haver mais uma forma de colaboração, involuntária talvez, em regime de certa divisão de trabalho. Assim, o uso do termo "ecologia" sugere a ocorrência de um sistema como de vasos intercomunicantes, tendente ao equilíbrio, que promove um sentido de preservação das hierarquias sólido e durável. É plausível pensar que, caso se consolidem políticas de responsabilização com sistemas de premiação (high-stakes), ou seja, consequências associadas a desempenho medido dos estudantes, poderemos ter futuramente alguma competição entre escolas como as aqui estudadas. Esse não é, contudo, um quadro já visível.

A primeira parte do artigo discute a literatura acerca dos quase-mercados educacionais e da escolha escolar. Em seguida, o texto apresenta um estudo de caso, levado adiante na cidade do Rio de Janeiro, que nos permitiu observar evidências

2 De um ângulo mais estritamente sociológico, essas escolas públicas comuns que gozam de prestígio diferenciado podem ser conceituadas como escolas de elite, dado que conferem acesso restrito a um bem escasso, de grande valor social. Teorias das elites podem ser exemplificadas com as lutas por confinamento e exclusividade de determinadas escolas. 
do funcionamento de mecanismos do que chamamos de um quase-mercado oculto. $\mathrm{Na}$ conclusão, levantamos questóes sobre as consequências da recusa em reconhecer a existência do quase-mercado nas redes públicas.

\section{Quase-mercado como recurso analítico}

Buscamos elementos conceituais em meio a uma literatura acerca de quasemercados $^{3}$ educacionais e escolha de estabelecimentos escolares (school-choice). Tal discussão proliferou diante da implementação de políticas, tais como o Ato de Reforma Educacional Britânico, de 1988, que aposta na competiçấo como força promotora do progresso.

Para os defensores de tais políticas, a liberdade de escolha de escolas leva à diversificação de oportunidades educacionais, uma vez que permite maior interação entre casa e escola e maior abertura das escolas para as demandas dos pais. Informação, escolhas disponíveis e análise custo-benefício seriam elementos importantes para o processo decisório dos pais que, supostamente, agem em um mercado escolar aberto, justo e não tendencioso (Berends; Zottola, 2009).

Diante da introdução de mecanismos com orientação de mercado, as escolas e os educadores teriam oportunidade e motivação para experimentar novas estratégias organizacionais e institucionais para atrair mais clientes. A combinação desses mecanismos, pelo lado da demanda e da oferta, traria como consequência maior autonomia, inovação e accountability das escolas e, consequentemente, melhores resultados escolares.

Mesmo entre os defensores de tais políticas, há o reconhecimento de suas fraquezas, das imperfeiçóes e das externalidades negativas que podem promover.

Por exemplo, a reforma britânica de 1988 teria permitido maior autonomia das escolas no processo de admissão, em detrimento das autoridades educacionais locais (Local Educational Authorities). As escolas de maior performance média, diante da maior procura, teriam adotado procedimentos para alcançar um influxo de alunos mais favorável, evitando alunos "difíceis de ensinar" (West, 2006; West; Pannell, 2002). Glennerster (1991) assinala que a tendência à seleção é forte entre as escolas, operando um previsível efeito de ampliação das desigualdades.

Estudos argumentam que a maior liberdade de escolha de estabelecimentos escolares não promove, necessariamente, maior eficiência das escolas e maior igualdade no sistema escolar. Isso porque os processos de escolha de estabelecimentos

3 Para Le Grand (199|), são "quase" mercados, pois incentivam a competição entre empreendimentos produtivos, em contraposição ao monopólio dos provedores estatais. Entretanto, tais empreendimentos não buscam necessariamente maximizar lucros, e o poder de compra dos consumidores não é expresso a partir de dinheiro, mas a partir de vouchers ou outros recursos de distribuição orçamentária, para consumir um serviço específico. 
escolares são complexos: os pais levam em conta diversos critérios, e os recursos de que dispóem para a escolha variam em funçáo dos grupos sociais a que pertencem.

Pais valorizam padróes acadêmicos altos, currículos fortes e boas práticas de ensino e, em geral, ranqueiam aspectos acadêmicos como o critério mais importante de escolha. Entretanto, a localizaçáo das escolas, o status socioeconômico e a composição racial também afetam sua decisão final. Berends e Zottola (2009) argumentam que pais com mais recursos selecionam escolas com composição de alunado de alto status socioeconômico. Mesmo que esse critério muitas vezes náo esteja dissociado de uma boa reputaçáo e bons resultados acadêmicos da escola, tal procedimento incentivaria as escolas a adotar açôes para atrair famílias de maior status socioeconômico, e não açóes de inovação organizacional para melhorar a qualidade, e menos ainda, a equidade educacional da escola.

De forma similar, Holme (2002) argumenta que, para além dos rankings oficiais, os julgamentos e a rotulação das escolas como más ou boas, gerados no âmbito de redes sociais, também influenciam as escolhas escolares. Em redes sociais, em especial aquelas restritas a moradores de vizinhanças de alto status, circulam não só informaçóes sobre o currículo da escola ou sobre a qualidade da instrução, mas opinióes de outros pais sobre a qualidade de escolas específicas (Holme, 2002). Ballion (apud Nogueira, 1998) defende que as escolhas de estabelecimentos escolares estão atreladas a um cálculo do tipo custo-benefício e dependem de diversos fatores: julgamento sobre o valor escolar do filho e apreciação de suas chances futuras, projeto educativo perseguido, informaçóes sobre o sistema de ensino, entre outros.

Bell $(2005,2006)$ mostra que os pais não dispõem todos dos mesmos recursos para a realização de suas escolhas. Seu estudo revela que eles consideram critérios acadêmicos como os mais importantes e que pais de diversas origens sociais usam formas aproximadas para escolher as escolas de seus filhos. Entretanto, o conjunto de escolas que consideram e a probabilidade de escolherem uma escola de alta performance são diferentes. Isso porque suas redes sociais os colocam em contato com uma gama diferente de escolas. Portanto, proponentes da escolha racional acertariam, ao afirmar que a motivação dos pais gira em torno da crença de que estejam selecionando as melhores escolas. Entretanto, tal perspectiva náo permite atribuir alguma racionalidade externa, objetiva, ao processo de escolha, já que diversas pesquisas demonstram que os pais acabam por optar por escolas às quais são mais expostos.

Berends e Zottola (2009) apontam que a maior parte do esforço de investigação sobre a matéria tem refutado premissas das políticas de escolha escolar, na medida em que se referem não somente a resultados de proficiência, mas aos três aspectos-chave que tais políticas pretendem incrementar: autonomia, inovação e responsabilização. Os autores afirmam, ainda, que há escassez de pesquisas que 
abordem o que ocorre na "caixa preta da escolha escolar". Pensam que é necessário investigar a estrutura e os processos sociais no interior das escolas, das suas classes e das famílias que possam promover sucesso escolar. Certamente, para os autores, isso não é dado.

Diante desses argumentos, são desconcertantes os resultados de investigaçóes expressas por Gorard e Fitz (2000) e Taylor e Gorard (2001): apresentam evidências de que a política de estímulo à school choice, no Reino Unido, a formalização de um quase-mercado educacional, tendeu a reduzir a homogeneidade de composição social das escolas, trazendo, por conseguinte, um pouco mais de equidade a um sistema que, pelos procedimentos de regionalização das matrículas, demarcava com nitidez fronteiras econômicas e étnicas no sistema escolar. Segundo os autores, a retomada de regras de fechamento distritais (restrição de matrícula por região de moradia), após 1998, produziu efeito de elevar a segmentação social entre as escolas.

Tomando a polêmica sobre políticas de quase-mercados educacionais, seus desenhos e consequências, adotamos, todavia, o conceito em uma dimensão sociológica. Consideramos que pensar nosso quadro nacional de distribuição de ofertas escolares em redes públicas de ensino básico, adotando o conceito de quase-mercado, permite ganhos analíticos no tratamento do fenômeno, sobretudo porque o contraste e as proximidades com padróes extranacionais se tornam mais evidentes.

\section{Quase-mercado escolar, no mundo e no contexto brasileiro}

No contexto brasileiro, encontramos a ausência de políticas oficiais que visem estabelecer quase-mercados escolares. Até muito recentemente, não havia, igualmente, qualquer iniciativa mais expressiva de políticas de responsabilização (recompensas, intervençóes, controles), nem mesmo de escolha de estabelecimentos escolares públicos ou competição por eles.

Ainda assim, é reconhecida a competição por vagas em instituições públicas que se distinguem das demais por sua boa reputação. As escolas de nível federal ou ligadas a universidades públicas, que desfrutam de condiçóes especiais de funcionamento, estão entre as mais procuradas ${ }^{4}$. Entretanto, o foco do presente estudo é um fenômeno menos visível: a disputa por escolas públicas comuns pertencentes às redes municipal e/ou estadual, que não frequentam o topo dos rankings, mas que estão longe de constituir um quadro homogêneo. Caracterizam-se por grande diferenciaçáo em termos do alunado e/ou dos resultados que obtêm em testes padronizados, tais como a Prova Brasil. Essa diferenciação é observada às vezes entre escolas localizadas no mesmo bairro, a poucas quadras de distância.

4 É importante ressaltar que tais escolas vêm substituindo mecanismos competitivos de acesso por provas, por outros procedimentos que introduzem alguma aleatoriedade no processo, como sorteios. 
Van Zanten (2005) argumenta que podemos pensar em competição por escolas públicas, mesmo na ausência de políticas que regulamentem ou incentivem tal competição. A autora argumenta que, em países em que a liberdade de escolha prevalece como valor (por exemplo, a Bélgica), o quase-mercado é mais francamente praticado. Já em países em que predomina o valor da igualdade, como a França, ele assume feiçôes mais ocultas, abarcando também seu deslocamento para dentro das escolas, na organização de turmas 5 . Davis e Quirke (2007) também encontram indícios em Toronto, Canadá, de um quase mercado, mesmo na ausência de uma cultura de testes padronizados e do estímulo de políticas oficiais.

Yair (1996) observa, no contexto de Israel, o funcionamento de mecanismos parecidos, embora não haja políticas de school choice. O autor propóe a "ecologia do mercado" como conceito básico para compreender o trânsito de alunos entre escolas. Para além do modelo individualista, segundo o autor, devemos pensar em resultados agregados das escolhas, como constrangimentos das próprias escolhas possíveis (elemento estrutural). Ele pensa em um sistema integrado, em que um tipo de escola permite a existência de outro. Por exemplo, escolas de maior seletividade dependem de outras que recebam os alunos que são delas expelidos.

Conforme a tese de Yair (1996), estudantes competem por escolas, mas escolas não apenas competem, como também colaboram, na divisão dos estudantes. Ao final, a ecologia do mercado escolar pode impedir ou, ao menos, limitar severamente, a escolha livre e o mercado livre .

De forma similar, podemos pensar no funcionamento de um quase mercado educacional no contexto brasileiro. Este, entretanto, como em outros, em que o quase-mercado náo constitui uma política educacional oficial, apresentaria características originais, dado que seus mecanismos são, deliberadamente, menos visíveis ou ocultos. Por isso, o chamamos de "quase-mercado oculto".

Podemos esperar que a população utilize sinais de classificação hierárquica de escolas - públicas e privadas - na busca por escolas para os seus filhos. A classificação hierárquica produz efeitos que podem ser identificados como uma disputa por posiçóes em um mercado, conforme delineado por Max Weber (1992), e mobilizam fortes noçôes hierárquicas, mesmo entre segmentos de baixo prestígio, poder e rendimentos, conforme descrito por Elias e Scotson (2000).

5 A autora relata que, na França, apesar de desaconselhada ou proibida a prática da organização intraescolar por grupos de habilidade, essa prática é disseminada, à revelia das autoridades escolares. Já em outros países, como a Hungria, ela é instituída.

6 Van Zanten (2005) refere-se a uma tipologia das escolhas que as escolas fazem de seus alunos, contendo três categorias, que vão de uma seletividade mais estrita para os estabelecimentos mais reputados, até a ausência de escolha para aqueles que "herdam" os não passíveis de admissão pelos demais.e refere a uma tipologia das escolhas que as escolas fazem de seus alunos. 
Por outro lado, as escolas e/ou as burocracias escolares e de nível intermediário da administração não são meros reagentes à demanda. Ao contrário do que preconizam as prescriçôes mais ortodoxas, elas participam de forma ativa, moldando a oferta e limitando as possibilidades de escolha. Uma vez que esta competição não é reconhecida ou visível, a falta de regulamentação do seu funcionamento daria margem ao funcionamento de mecanismos de seleção pouco claros, se comparados com os quase-mercados oficialmente instituídos.

Buscamos, assim, compreender os mecanismos pelos quais a escolha de escolas pode encetar a formação de um quase-mercado oculto, que, na ausência de regulamentaçáo, gera e alimenta processos de desigualdades de oportunidades educacionais. Na próxima seção, analisaremos algumas entrevistas e pequena parte dos dados de uma pesquisa quantitativa, que identificam alguns dos mecanismos pelo quais esse fenômeno ocorre e suas possíveis consequências para a estratificação escolar.

\section{Evidências do funcionamento do quase-mercado oculto: o contexto do Rio de Janeiro}

Para iniciar nossa tentativa de caracterizar o funcionamento do assim chamado quase-mercado oculto no contexto da cidade do Rio de Janeiro, analisamos entrevistas realizadas com 20 professores e 5 diretoras da rede municipal de Ensino Fundamental, bem como 20 entrevistas com pais de alunos ${ }^{7}$. Tentamos observar os mecanismos pelo lado da demanda, buscando identificar: (i) os critérios utilizados pelos pais para escolher os estabelecimentos escolares de seus filhos; (ii) evidências sobre o papel das redes na formação e na circulação de informação sobre a reputaçáo das escolas. No que diz respeito ao lado da oferta no quase-mercado oculto, atentamos para sinais dos possíveis processos utilizados pelas escolas para "selecionar" seus alunos.

\section{Demanda: critérios da escolha e o papel das redes sociais}

A partir dos critérios usados pelos pais, escolhemos as escolas foco de nossa pesquisa: escolas públicas de Ensino Fundamental da rede municipal do Rio de Janeiro. Entre os critérios mencionados por eles, diversos motivos se aproximam do tipo descrito por Ballion como escolhas por conveniência prática. A mais fre-

7 As entrevistas aqui mencionadas correspondem à fase inicial de um projeto de pesquisa em curso, que pretende associar esse procedimento exploratório à realização de um survey domiciliar. As entrevistas com pais foram obtidas por critério de conveniência, a partir de contatos com integrantes da equipe de pesquisa, especialmente alunos de graduação. As demais entrevistas foram provenientes de investigações anteriores, de projeto de pesquisa em fase de conclusão e algumas originais. Os extratos aqui apresentados exprimem percepções recorrentes em diversas entrevistas. 
quente no discurso dos pais é a proximidade da residência: "Primeiro porque é a escola que eu estudei e segundo pela proximidade do meu local de residência".

Mesmo quando os pais matriculam seus filhos longe de seu local de residência, registramos critérios de conveniência prática para tais escolhas, tais como a proximidade ao local de trabalho dos pais:

- Epor que você escolheu a Gávea?

- Porque eu trabalho aqui e ela já vem comigo.

Mesmo os pais que realizam a escolha por características educativas focalizam mais em fatores relacionados à disciplina e à organização da escola do que no desempenho acadêmico. A segurança aparece como importante fator:

- E por que a escolha pela Escola X e náo, por exemplo, pela $Y^{8}$ ?

- Mais pela estrutura do Forte, porque lá, como tem segurança porque é uma escola dentro do Forte XX, a gente se sente mais seguro.

A visão da "qualidade" da escola também é formada a partir de características organizacionais da escola:

- Mas por que a escolha da Escola Z?

- Porque já era uma escola que a gente tinha referência de ser uma escola boa, por ser pequena, poucos alunos, tinha a diretora que diziam que era muito boa, que a escola era sempre muito organizada.

Ainda é interessante notar que os pais usam as suas redes sociais para obter informação sobre a escola:

- Minha vizinha de rua. Eu, conversando com ela, disse que queria uma escola que a turma não fosse muito grande e agitada... E essa minha vizinha me indicou esta escola, disse que é como uma escola particular.

Quando conseguiram vagas em escolas de alto prestígio, frequentemente mencionam redes sociais como forma de acesso a uma vaga:

- Como que a sua filha teve acesso a essa escola?...

- ... foi por indicação que ela conseguiu. Imagino que sem a indicação fosse mais difícil.

- E na Escola W, como a senhora conseguiu vaga para as duas meninas?

8 Ambas são escolas de boa reputação, na mesma região, mas com nítida vantagem para a Escola Y. A primeira escola fica dentro de uma unidade militar. 
- Porque eu conhecia a diretora.

- E na Escola Q?

- Porque eu também conhecia a diretora.

- Então foi garantida a vaga deles. Sem entrar em fila.

- Sim, sem fila. Inclusive foi a própria diretora da Q que deu uma grande ajuda indicando os três.

Como veremos mais adiante, o tipo de escolha tem grande impacto sobre a probabilidade de os pais matricularem seus filhos em escolas de maior prestígio, mesmo que os critérios relacionados a resultados escolares não apareçam de forma clara em suas falas.

Além disso, observamos a importância das redes sociais tanto para o acesso a informaçóes sobre a reputação de escolas como para o acesso a vagas nessas escolas de maior reputação. Se Bell $(2005,2006)$ aponta resultados desiguais gerados pelas escolhas de pais com diferentes origens e redes sociais, mesmo na presença de sinais claros informando a school-choice, podemos esperar que, no caso brasileiro, na ausência de sinais claros, a diferenciação das oportunidades de escolha seja ainda mais pronunciada.

No Rio de Janeiro, onde não há restrições de ordem geográfica para a matrícula em escolas de Ensino Fundamental, observamos escolas com menor prestígio, pouco procuradas por pais, e aquelas com prestígio mais elevado, que enfrentam grande demanda. A partir da realização de entrevistas com professores e diretores de escola, pudemos observar que, na ausência de regras formais para seleção de alunos, diversos mecanismos obscuros entram em vigor na seleção em que alunos terão acesso às escolas de maior prestígio.

Oferta: evidências sobre a seleção dos alunos

Uma breve descrição dos procedimentos regulares de matrícula no Rio de Janeiro 9 indica caminhos pelos quais o quase-mercado escolar opera, no âmbito das escolas municipais.

A maioria das escolas concentra seus alunos em um segmento do Ensino Fundamental ou Infantil. Poucas cobrem desde a Educação Infantil até o segundo segmento do Fundamental. Mesmo essas, porém, não costumam ter uma oferta regular de vagas que assegure a estabilidade de seu alunado. É comum haver aumento ou redução de turmas na transição de um para outro segmento. Ocorre, portanto, intensa movimentaçáo de alunos entre escolas, parcialmente regulada nos polos de matrículas - subdivisóes em grupos de oito ou dez escolas, com proximidade geográfica e oferta de segmentos diversos de ensino.

Há, basicamente, quatro fases na atribuição de matrículas de alunos. A primeira é o chamado remanejamento. No segundo semestre letivo, as direçóes

9 Procedimentos em vigor até 2009. 
solicitam a pais e responsáveis de alunos em vias de conclusão do segmento que preencham uma lista ordenada com três escolhas de escolas - desde que constem do polo de matrícula - para remanejamento de seus alunos. A partir dessas escolhas, as escolas se reúnem, e as vagas das escolas receptoras são distribuídas entre as que enviam alunos. Há, como regra geral, que algumas escolas de segmentos diferentes são como que associadas a determinadas outras. Assim, alunos de uma escola de primeiro segmento têm vagas preferenciais asseguradas em outra de segundo segmento.

A segunda etapa consiste na oferta das vagas remanescentes, não preenchidas, diretamente à demanda pública, em datas predefinidas. Cada polo de matrícula, com todas as suas escolas, se reúne em um mesmo local e candidatos às vagas são atendidos em sistema de matrícula informatizada. Cada vaga disponível pode ser ali ofertada, e mesmo alunos que já disponham de vaga assegurada em alguma escola na fase anterior podem, nessa ocasião, efetuar uma troca. Alunos provenientes de fora do sistema também podem ingressar.

Uma terceira etapa ocorre diretamente nas escolas, desde que estas ainda disponham de vagas. As direçôes das escolas, então, efetuam diretamente suas matrículas.

Por fim, pode-se considerar a existência de uma quarta fase, que se processa ao longo do ano escolar, também diretamente nas escolas.

Como se pode observar, não há exatamente um processo desregulado. Regras e procedimentos formais são estabelecidos. O resultado, entretanto, facilmente perceptível através de simples visita a escolas, sugere ausência de aleatoriedade. As escolas tendem a certa homogeneidade socioeconômica. No caso do Rio de Janeiro, esse flagrante desfecho não pode ser ofuscado pela distribuição regional da desigualdade social. Nosso padrão de ocupação urbana, o modelo carioca de segregação residencial combina proximidade geográfica com distância social (Ribeiro; Alves; Franco, 2008). As favelas espalhadas por toda a cidade conturbam um modelo clássico de segregação em círculos geográficos concêntricos. Apesar disso, essa mistura não se expressa em algumas escolas - exatamente as mais prestigiadas.

Nosso desafio é compreender os mecanismos pelos quais a segmentaçấo escolar vai se construindo ao longo de um processo de recrutamento escolar, na quase ausência de procedimentos formais, regulamentados. Não há distritalização de matrículas - as vagas são formalmente livres a qualquer postulante, independentemente de seu local de residência. No caso do Rio de Janeiro, a distância física não pode ser argumento para a diferença de composição socioeconômica, em maior parte da cidade. Não há, ainda, qualquer aferição formal de desempenho associada à seleção de ingresso por esse critério.

Construímos um modelo esquemático, o que nos permite formular as seguintes hipóteses: 
1) A segmentação socioeconômica - e de desempenho - entre as escolas começa bastante cedo. A formação de circuitos virtuosos e viciosos se dá a partir da creche ou da Educação Infantil, pelo tipo (prestígio) da escola na qual se ingressa na primeira vaga. Esse mecanismo opera por meio do remanejamento de vagas na primeira fase de matrícula, em que algumas escolas encaminham preferencialmente alunos para outras de prestígio equivalente. A distribuição de vagas nesse remanejamento entre escolas de um mesmo polo de matrícula não obedece a critérios de aleatoriedade. Direçóes de escolas oferecem blocos de vagas às escolas demandantes. Dessa forma, escolas que gozam de alto conceito tendem a oferecer suas vagas preferencialmente a alunos de escolas que lhes seriam equivalentes. Portanto, o tipo de percurso escolar seria fortemente marcado pela primeira vaga conseguida. Tivemos, mesmo, o depoimento de uma diretora de escola de Educaçáo Infantil que, relatando sua participação em uma reuniáo de polo de matrícula, observou a direçáo de uma escola bastante procurada informar que náo abriria qualquer vaga para a demanda de dois CIEPs que compunham o mesmo agrupamento ${ }^{10}$. Nessa mesma escola, por exemplo, têm vagas asseguradas todos os alunos provenientes de uma escola de Educação Infantil próxima, que atende a uma populaçáo de mesmo perfil.

2) Com uma grande rede escolar pública, em meio a uma grande metrópole, ajustes vão ocorrendo ao longo do percurso escolar. Assim, todas as fases descritas acima, nas quais é possível conseguir uma vaga em alguma escola, são permeáveis à decisão discricionária por integrantes da burocracia educacional. No remanejamento entre escolas, tivemos relatos de distribuição desigual, por critérios que parecem levar em conta fatores adscritos dos alunos. Há dois níveis nessa decisão. No primeiro, a escola que recebe alunos pode privilegiar vagas para aqueles que lhe sejam mais próximos, do ponto de vista da composiçáo social. No segundo nível, atribuídas essas vagas, a burocracia das escolas "fornecedoras" de alunos decide quais deles terão seus pleitos aceitos. Dessa forma, alunos mais "adequados" a uma ou outra escola vão sendo encaixados em escolas nas quais, supostamente, encontrarão maior afinidade. Na segunda e na terceira fase, igualmente, é possível que escolas mais demandadas admitam alunos oriundos de determinada escola, mas não de outra. Área de moradia e demais caracteres socioeconômicos podem ser considerados, dado que não há obrigação de aceitar um aluno, havendo vaga em outra escola da área. Reforçando a primeira tese acerca do caráter precoce da definição de trajetórias escolares, nesse contexto, um critério sempre relatado se refere a prioridades em vagas para irmãos já matriculados em uma escola.

Esquematicamente, um estudante cuja família consiga vaga em uma creche municipal (sabemos que há escassez relativa dessas vagas) tem aumentadas suas

10 Como é corrente no Rio de Janeiro, os CIEPs estão entre as escolas de mais baixo prestígio, sendo caracterizados como escolas destinadas aos mais pobres, aos favelados. O depoimento citado no texto foi colhido em 2007. 
probabilidades de iniciar um percurso por escolas que gozam de melhor reputação em meio à rede pública. Essa probabilidade, porém, não se esgota aí, estendendo-se a seus irmãos mais novos, que terão maior chance de acesso a tais escolas. Trajetória oposta é mais provável para aqueles que, desprovidos de capital social, iniciem sua escolarização mais tardiamente e/ou em escolas que desfrutem de menor prestígio relativo.

O trecho de uma entrevista realizada com uma professora da rede ilustra como funciona o remanejamento de alunos entre as escolas:

- A criança estudava nessa escola da comunidade e ela, por estudar nessa escola, é mais fácil entrar na Escola $S$ ou não?

- ... Determinadas escolas mandam direto para outras. Isso existe, sim. Por exemplo, essa escola que eu tava, da tarde [...], as crianças que entravam lá, no início, vinham direto, por exemplo, a minha turma era toda da Escola J, que é lá nos Prazeres... Não necessariamente que todos tenham que ir pra lá, mas a indicação é daqui para lá.

Escolas que gozam de maior prestígio enfrentam com menor intensidade o dilema de ter que escolher quais alunos remanejar para aquelas com prestígio equivalente, dado que tendem a receber mais vagas destas. Já nas escolas com menor reputação, provavelmente, mais "escolhas de Sofia" devem ser inevitáveis.

3) À escolha das famílias conjuga-se a das escolas, que podem exercer ação "pedagógica" sobre aquelas, conduzindo e ajustando as famílias a suas próprias opçôes. $\mathrm{O}$ aconselhamento e a ascendência técnica exercidos pela burocracia escolar influenciam as decisóes familiares. Tivemos relatos dessa ascendência, que procuraria desestimular uma escolha familiar com o argumento pedagógico da grande chance de que alunos fossem reprovados em uma escola mais exigente, caso supostamente não apresentassem potencial para acompanhar seu ritmo. Evitar a frustração e o risco de uma trajetória escolar truncada parece funcionar como argumento limitador de aspirações de acesso a escolas de maior prestígio.

As direçóes escolares tendem a adotar argumentos pedagógicos e de caracterização individual dos alunos para explicar a alocação que fazem de seus alunos enviados a escolas ordenadas na hierarquia escolar raramente admitida, mas facilmente observável.

As seguintes falas ilustram alguns dos critérios informais utilizados pelas diretoras de escolas de alto prestígio na seleção de seus alunos:

Eu lembro que uma vez uma mãe foi fazer uma matrícula, aía diretora falou assim: "Não, não. Não tem vaga não". Aí eu falei: "Poxa, Lucia, você não vai dar vaga pra menina não? Essa ai é a irmã do Igor, um menino muito bom". Aí ela falou: "Aquele 
Igor, que escrevia aqueles textos bons pra caramba?" Eu falei: "É!!". Ai ela gritou a mulher e mandou chamar ela de volta e conversou com ela e a irmá do menino conseguiu a vaga, entendeu? Tem uma seleção de até quem vai entrar e quem não vai. Se a direção da escola puder pegar aquele aluno que ela sabe que vem de uma família participativa, que se preocupa em dar apoio à criança em casa e tudo mais, ela pega; e, se puder descartar aquele que ela vê que vai dar problema para a escola, porque já conhece o "histórico" do aluno, ai ela descarta. - ...pode acontecer, ai não é só aqui; é em todas as escolas, de se você tiver uma direção que abra uma brechinha pra assim, mais um aluno. Chegou uma pessoa... É sempre maleável... E você é conhecido de alguma pessoa que fala assim - "não, preciso muito pra essa criança, tem como colocar?". Ai depende... Ela analisa, depende da direção, da quantidade de aluno por turma, se pode ainda, se pode extrapolar o limite, dependendo da turma... É maleável. Mas tem um limite certo. Isso são casos especiais.

De outro lado, observamos que escolas de baixo prestígio e com maior número de vagas disponíveis acabam acolhendo alunos indesejados por outras escolas da rede:

- Aqui eles vão seguindo com dificuldade, eles vêm de outras escolas onde já deram problema e vêm pra cá. Se você for observar os alunos problemáticos desta escola, os alunos novos que vieram pra cá este ano e for verificar, eles já vêm de pelo menos duas escolas daqui da Ilha mesmo. E eu não sei por que, aí não me pergunta por quê?? Por que eles caem tudo aqui? [...].

- Teve esse caso. Ela pegou uma arma do tráfico, assaltou o açougue e prendeu o velhinho lá dentro. Ela foi presa, agora tá solta, e aonde ela está estudando? Aqui. E a diretora fala: "Não é possível, tudo vem pra cá!". Mas tem que ser aqui, entendeu? Então, como éque pode o indice ser bom? Vai juntando um grupo bem característico.

4) A permeabilidade do sistema o torna suscetível, ainda, a influências do que podemos caracterizar como patrimonialismo e clientelismo. Inúmeros são os relatos colhidos acerca de interferências políticas na obtenção de vagas. Também demandas emanadas no interior da própria burocracia educacional tendem a impor-se. Apesar de evitar tocar no assunto, as direçóes de escolas mais prestigiadas não chegam a refutar o fato de que precisam atender a demandas que correm por fora dos caminhos formalizados. Os recursos utilizados são a não oferta de todas as vagas disponíveis nas etapas de matrícula centralizadas e o aumento do número 
de alunos em turmas que já haviam alcançado sua lotação. Forma-se, assim, como que uma reserva de vagas a serem preenchidas diretamente pela direçáo escolar. Reciprocidade no acesso a algum favor parece estar na base de tal sistema de troca, inclusive entre integrantes da própria burocracia educacional.

\section{quase-mercado oculto e a hierarquização do sistema escolar}

Como resultado, podemos esperar um sistema altamente hierarquizado, a partir de critérios fluidos, aparentemente associados a mecanismos de seleção por origem social e por redes de contatos. Um survey realizado em seis escolas municipais de Ensino Fundamental do Rio de Janeiro traz evidências da hierarquização do sistema escolar público ${ }^{11}$.

Os dados foram organizados por escola, tendo sido adotada denominaçáo que indica a área de cidade em que se encontram, acrescida de um sinal + ou -, para indicar o prestígio relativo da escola, na comparação com sua correspondente geográfica. Assim, são duas escolas para cada zona escolhida na cidade (Norte, Tijuca e Sul), com prestígio positivo ou negativo. Dessa forma, quando nos referirmos à escola $\mathrm{T}+$, estaremos tratando da escola considerada de alto prestígio situada na Tijuca. Da mesma forma, a escola N-é a situada na Zona Norte, gozando de baixo prestígio. Há forte distinção socioeconômica entre essas áreas. A essa desigualdade somam-se profundas diferenças no acesso a serviços públicos, bens culturais, etc. A regiâo mais pobre e mais desprovida de bens e serviços é a Zona Norte, seguida da Tijuca e adjacências, e, em seguida, pela Zona Sul - a regiáo economicamente mais afluente da cidade ${ }^{12}$.

Os resultados apresentam forte diferenciação socioeconômica entre as escolas, segundo as regióes da cidade, mas também intrarregional.

II Os referidos dados foram obtidos a partir de um survey realizado no segundo semestre de 2006. Estudantes de $5^{\mathrm{a}}$ a $8^{\mathrm{a}}$ séries recebiam um questionário com 55 questões, versando sobre sua vida escolar pregressa; a composição de sua família; suas características demográficas gerais; hábitos e práticas cotidianos; percepções e expectativas; seu meio de convivência; e, por fim, inúmeros aspectos de sua escola atual.

12 Entretanto, de acordo com Ribeiro, Alves e Franco (2008), apesar da distinção entre a Zona Sul e de pequena parte da Zona Norte, que constituem as áreas mais abastadas da cidade, e as demais partes da Zona Norte e os espaços periféricos mais populares, características marcantes do modelo de segregação residencial da cidade do Rio de Janeiro são a proximidade física e a distância, na hierarquia social, entre segmentos que ali possuem posições opostas. A presença de favelas ao longo da cidade e a concentração destas nas partes mais abastadas são expressões claras desse modelo de segregação residencial. Entretanto, a concentração de diferentes segmentos sociais em um mesmo território não implica em maior interação ou no estabelecimento de laços sociais que poderiam permitir a superação das distâncias sociais.

Pro-Posiçóes, Campinas, v. 23, n. 2 (68), p. 195-213, maio/ago. 2012 
Gráfico I - Nível socioeconômico (padronizado), por escola, na amostra

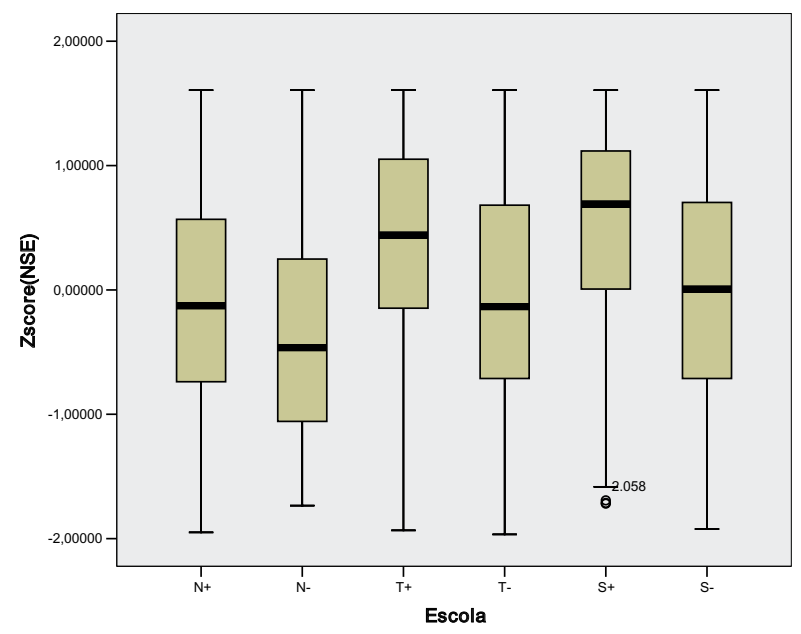

Fonte: Survey escolar realizado pela pesquisa

Quadro I - Distribuição do resultado na Prova Brasil 2007, por escola, segundo padrões de demanda e oferta

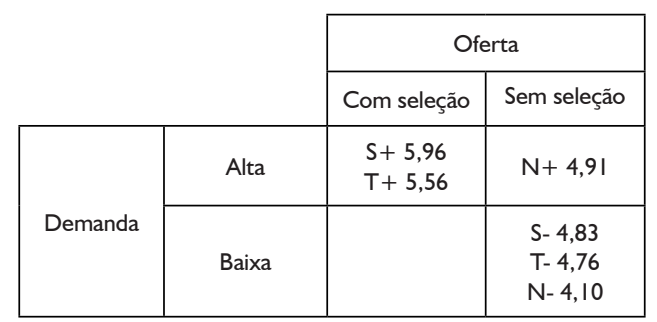

Fonte: Prova Brasil (INEP)

Os contrastes são claros em dois sentidos: em termos regionais e entre escolas em uma mesma área. As escolas nas áreas mais abastadas da cidade tendem a receber um alunado de maior nível socioeconômico. Entretanto, considerando que as escolas de baixo prestígio estão localizadas próximas aos seus pares de alto prestígio, as diferenças de nível socioeconômico entre as escolas na mesma área não podem ser explicadas de forma satisfatória pelo espaço geográfico em que estão localizadas.

No Quadro I, para além da hierarquização referente a diferenças socioeconômicas da populaçáo residente em cada área da cidade, observamos a seguinte tendência:

1) no primeiro quadrante (esquerdo superior) estão as escolas $(S+e T+)$ que, pelo lado da demanda, são caracterizadas pela predominância de pais que dizem tê-las escolhido a partir do critério de qualidade e/ou pelo prestígio de que gozam. Pelo lado da oferta, nelas foi observado o uso de certos critérios informais de seleção 
do alunado. É interessante notar que, entre as escolas estudadas, são estas as que apresentam a maior média do nível socioeconômico dos alunos e as que alcançam maior nota no Ideb de 2007.

2) no segundo quadrante (direito superior) está a escola ( $\left.\mathrm{N}_{+}\right)$. Pelo lado da demanda, ela é procurada por pais que buscam uma escola de maior prestígio/ qualidade. Entretanto, pelo lado da oferta, é caracterizada por ter acesso mais universal, se comparada com as escolas $S+$ e $T+$. Apesar de ter alunos com um nível socioeconômico parecido com as escolas $S$ - e T-, apresentou um Ideb ligeiramente mais alto do que elas.

3) No terceiro quadrante (direito inferior) encontramos as escolas S-, T- e $\mathrm{N}$-, cuja demanda se caracteriza pela predominância de pais que disseram ter escolhido a escola por proximidade de sua residência; e, no lado da oferta, ali náo foi observado o uso de critérios informais para a seleção dos alunos. Apresentam alunos com nível socioeconômico inferior e Ideb mais baixo, se comparadas com as escolas do primeiro quadrante.

Por fim, apesar de as evidências acima estarem baseadas em um estudo que considerou somente seis escolas da rede municipal de Ensino Fundamental, a divisão delas, de acordo com o tipo de oferta de vagas e o tipo de escolha dos pais, parece ilustrar a estreita relaçáo entre o funcionamento de mecanismos do quasemercado oculto e a hierarquização das escolas dessa rede.

\section{Comentários finais}

As evidências encontradas justificam o uso do conceito de "quase-mercado oculto"? É oculto porque não há mecanismos formais, explícitos, de seleção de alunos em cada estabelecimento. Sáo procedimentos velados que permitem a algumas escolas operar ativamente no mercado, que, do ponto de vista legal e formal, não é nem pode ser fechado. Há vagas para todos - ao menos no nível de ensino estudado. A rede pesquisada, assim como as demais redes públicas que conhecemos no Brasil, náo dispóe de procedimentos - testes de acesso ou mecanismos legais de exclusão e seleção - que permitam filtrar claramente seus alunos. No entanto, há forte seletividade por parte de alguns estabelecimentos mais conceituados, o que ocorre de forma velada. A existência de uma parca independência de gestáo escolar - mesmo que esta náo tenha sido estimulada por uma política deliberada - tem levado a artifícios de "esconder vagas", ou à rejeição de alunos ${ }^{13}$. A evasão - normalmente transferência - é algo operado sutilmente, por meio do apelo frequente aos pais e da sugestão de uma alternativa escolar mais "condizente" com o perfil escolar do aluno indesejado.

13 Nossa pesquisa qualitativa colheu evidências de recusa por parte de algumas escolas em receber alunos de determinadas outras ou de oferta, nos espaços formais para trânsito de alunos entre estabelecimentos escolares, de número de vagas mais reduzido do que seria esperado. 
Este trabalho procurou levantar hipóteses que permitam compreender o marcante quadro da desigualdade social manifesta na desigualdade de oportunidades escolares no Brasil. Um estudo de caráter exploratório, no Rio de Janeiro, foi usado como ponto de partida à articulação de uma pesquisa mais abrangente geográfica e metodologicamente, ora em curso. Ainda assim, foi possível constatar o funcionamento de um quase-mercado oculto no contexto da rede municipal de Ensino Fundamental na cidade do Rio de Janeiro, mesmo que os pormenores de seu funcionamento ainda precisem de mais investigação para que sejam mais claramente compreendidos.

Várias pessoas no contexto brasileiro investem contra a "escolha" com base em argumentos de estratificação e desigualdade e a partir da defesa de princípios universalistas e includentes que não condizem com a real organização da rede. James Coleman (1992), um dos pilares da sociologia da educação, já alertava, quando essa discussão ainda não tinha grande repercussão, que a ausência de políticas de regulação da escolha escolar não significa que a estratificação pela via das oportunidades escolares possa ser evitada.

Nosso estudo destaca que, sem a presença de componentes deliberados de atenção à distribuição de oportunidades no seio das redes públicas de ensino, a situaçáo de quase-mercado existente no contexto brasileiro pode contribuir para amplificar, naquilo que se refere ao alcance da escolarização, nossos padrões de desigualdade social.

Preocupaçóes que se adensam sobre problemas de qualidade educacional, no Brasil, podem voltar sua atenção, também, para questôes de equidade de oportunidades, especialmente para a distribuição de acesso e o intenso trânsito de alunos entre escolas, que marcam nossos sistemas escolares, mas que vêm sendo ignorados na sociologia da educaçáo. Parte da imobilidade nos padróes de disparidades educacionais brasileiras pode encontrar nesse campo elementos de compreensão.

\section{Referências bibliográficas}

BELL, C. A. All Choices created equal? How good parents select "failing" schools.

New York: Columbia University, National Center for the Study of Privatization in Education, 2005. Disponível em: <http://www.ncspe.org/publications_files/OP106.pdf>. Acesso em: 22 jun. 2008.

BELL, C. A. Real Options? The Role of Choice Sets in the Selection of Schools. Teachers College Record, jan. 2006. Disponível em: <http://www.tcrecord.org>. Acesso em: 9 set. 2009.

BERENDS, M.; ZOTTOLA, G. C. Social Perspectives on School Choice. In: BERENDS, M. et al. (Org.). Handbook of Research on School Choice. New York/London: Routledge, 2009. p. 35-53. 
BRADLEY, S.; CROUCHLEY, R.; MILLINGTON, J.; TAYLOR, J. Testing for quasimarket forces in secondary education. Oxford Bulletin of Economics and Statistics, v. 62, n. 3, p. 357-390, jul. 2000.

COLEMAN, J. S. Some Points on Choice in Education. Sociology of Education, v. 65, n. 4, p. 260-262, out. 1992.

DAVIES, S.; QUIRKE, L. The Impact of Sector on School Organizations: Institutional and Market Logics. Sociology of Education, v. 80, n.1, p. 66-89, jan. 2007.

ELIAS, N.; SCOTSON, J. L. Os estabelecidos e os outsiders. Sociologia das relaçóes de poder a partir de uma pequena comunidade. Rio de Janeiro: Zahar, 2000.

GLENNESTER, H. Quasi-markets for education? The Economic Journal, London, v.101, n. 408, p. $1268-76,1991$.

GORARD, S.; FITZ, J. Investigating determinants of segregation between schools. Research Papers in Education, v. 15, n. 2, p. 115-132, jun. 2000.

HOLME, J. J. Buying Homes, Buying Schools: School Choice and the Social Construction of School Quality. Harvard Educational Review, v. 72, n. 2, p.177-205, jun./ ago. 2002.

LE GRAND, J. Quasi-Markets and Social Policy. The Economic Journal, v. 101, n. 408, p. 1256-1267, set. 1991.

NOGUEIRA, M. A. A escolha do estabelecimento de ensino pelas famílias: a ação discreta da riqueza cultural. Revista Brasileira de Educação, n. 7, p. 42-56, jan./abr. 1998.

RIBEIRO, L. C. Q.; ALVES, F.; FRANCO, C. Segregación urbana y rezago escolar em Rio de Janeiro. Revista de la Cepal, n. 94, abr. 2008.

TAYLOR, C.; GORARD, S. The role of residence in school segregation: placing the impact of parental choice in perspective. Environment and Planning A, v. 33, n. 10, p. 1829-1852, out. 2001.

VAN ZANTEN, A. Efeitos da concorrência sobre a atividade dos estabelecimentos escolares. Cadernos de Pesquisa, v. 35, n. 126, p. 565-593, set./dez. 2005.

WEBER, M. Economia y sociedad. Ciudad de Mexico: Fondo de Cultura Económica, 1992.

WEST, A. School Choice, Equity and Social Justice: The Case for More Control. British Journal of Educational Studies, v. 54, n. 1, p. 15-33, mar. 2006.

WEST, A.; PANNELL, H. How New is New Labour? The Quasi-Market and English Schools 1997 to 2001. British Journal of Educational Studies, v. 50, n. 2, p. 206-224, dec. 2002.

YAIR, G. School Organization and Market Ecology: a Realist Sociological Look at the Infrastructure of School Choice. British Journal of Sociology of Education, v. 17, n. 4, p. 453-471, 1996.

Recebido em 01 de abril de 2011 e aprovado em 18 de outubro de 2011. 
